\title{
Global patterns of declining temperature variability from the Last Glacial Maximum to the Holocene
}

\author{
Kira Rehfeld, ${ }^{1,2 *}$ Thomas Münch, ${ }^{1,3}$ Sze Ling Ho ${ }^{1,4}$, Thomas Laepple ${ }^{1}$ \\ ${ }^{1}$ Alfred-Wegener-Institut, Helmholtz-Center for Polar and Marine Research \\ Telegrafenberg A43, 14473 Potsdam, Germany \\ ${ }^{2}$ British Antarctic Survey, High Cross, Madingley Road, Cambridge, CB3 0ET, UK \\ ${ }^{3}$ Institute of Physics and Astronomy, University of Potsdam, \\ Karl-Liebknecht-Str. 24-25, 14476 Potsdam, Germany
}

${ }^{4}$ University of Bergen and Bjerknes Centre for Climate Research, Allégaten 41, 5007 Bergen, Norway

This is a post-print PDF.

The publisher's version can be found here: http://www.dx.doi.org/10.1038/nature25454

Changes in climate variability are as important for society to address as are changes in mean climate[1]. Contrasting temperature variability during the Last Glacial Maximum and Holocene can provide insights into the relationship between the mean state of climate and its variability[2,3]. However, although glacial-interglacial changes in variability have been quantified for Greenland[2], a global view remains elusive. Here, we use a network of marine and terrestrial temperature proxies to show that temperature variability decreased globally by a factor of 4 as the climate warmed by 3- 8 degrees Celsius from the Last Glacial Maximum (around 21,000 years ago) to the Holocene epoch (the past 11,500 years). This decrease had a clear zonal pattern, with little change in the tropics (by a factor of only 1.6-2.8) and greater change in the mid-latitudes of both hemispheres (by a factor of 3.3-14). By contrast, Greenland ice-core records show a reduction in temperature variability by a factor of 73 , suggesting influences beyond local temperature or a decoupling of atmospheric and global surface temperature variability for Greenland. The overall pattern of reduced variability can be explained by changes in the meridional temperature gradient, a mechanism that points to further decreases in temperature variability in a warmer future.

There is scientific consensus that the mean global temperature has been rising over the instrumental era[4]. However, whether this warming has caused surface temperatures to become more[5] or less[6, 7] variable, and how this 
variability will change in a warmer future, remain topics of debate. Here we use paleoclimate proxy data to quantify changes in temperature variability before and after the last major transition in global mean climate: the 3-8 degree warming[8] from the Last Glacial Maximum (LGM, around 21,000 years (21 kyr) ago) to the current warm period of the Holocene (Fig. 1). The magnitude of temperature change during this transition is in the same range as that projected for the coming centuries[4].

The global spatial pattern of the mean LGM-to-Holocene temperature change has been established through numerous studies[8, 9, 10]. However, except for some studies on changes of interannual climate variability in the tropics[11], our current understanding of variability changes is largely based on the stable oxygen isotope records of the high-resolution central Greenland ice cores[12]. The isotope records, which are interpreted as proxy for temperature[13], show that the last glacial period appears to have been not only cold but also highly variable on decadal to millennial timescales $[2,3]$. This finding is not limited to the magnitude of distinct events, such as the Heinrich stadials (i.e. cold periods in Greenland) or the abrupt transitions into the Dansgaard-Oeschger (DO) interstadials; it also holds for the background variability during the LGM (Fig. 1b).

Consequently, glacial climate has been characterized as highly variable[2, 3] whereas the Holocene is commonly described as a stable and quiescent period[3]. The large reduction in variability was proposed to have supported human dispersal throughout Europe[14] and cultural evolution[15]. However, the evidence for an exclusively stable Holocene climate - beyond that of Greenland ice-core records - is unclear, particularly because other proxy records for temperature in and outside of Greenland suggest considerable variability during the Holocene[16, 17].

In this study, we derive a quantitative estimate for global and regional change in temperature variability between the LGM (27-19 kyr ago) and the Holocene (8-0 kyr ago) based on high-resolution palaeoclimate proxy records for temperature (Fig. 1a). These time periods represent rather stable boundary conditions with minimal changes in ice-sheet size and sea level. Furthermore, our LGM time window only contains one small Dansgaard-Oeschgerevent, thereby enabling us to focus our analysis on the glacial background state. We compile two global datasets (Methods). The first ('joint') dataset contains 28 records which cover both the LGM and the Holocene. We estimate the change in variability from the ratio of LGM to Holocene variance separately for each record and thus independently of calibration uncertainties, as long as the calibrations are constant over time. This is a reasonable assumption as state-dependent calibrations have only been proposed for Greenlandic ice cores[18] and we take this into account. Analysing variance ratios from single cores also minimizes site-specific effects on the variance estimates, such as the ecological preferences of the organisms that record the climate signal or the extent of bioturbation, which affects marine proxies in sediments (Methods). The second ('separate') dataset is more 


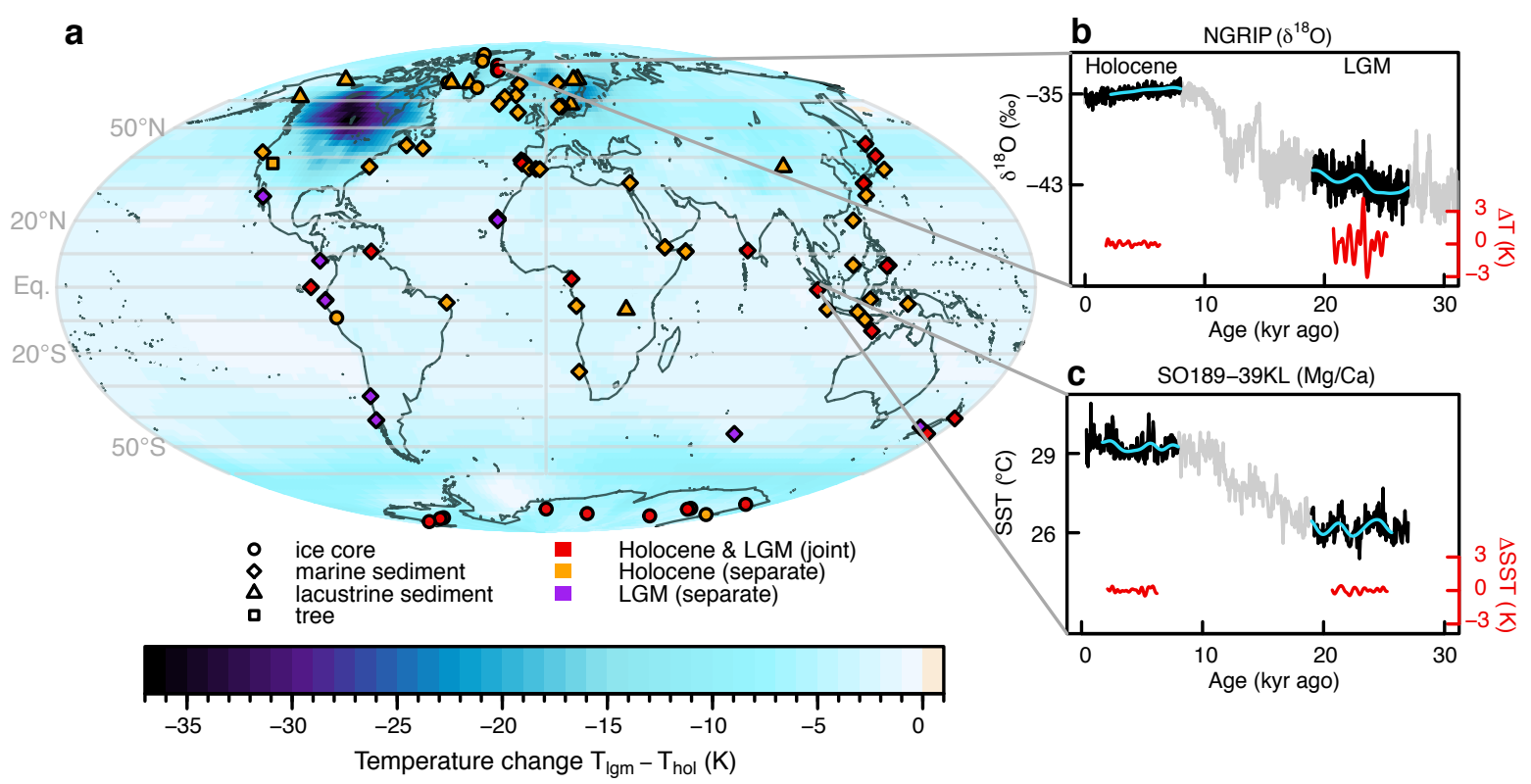

Figure 1: Proxy records for temperature. a, Site locations (symbols) and mean LGM-to-Holocene temperature change $\left(\mathrm{T}_{\operatorname{lgm}}-\mathrm{T}_{\text {hol }}\right.$; background) estimated from climate model and proxy data[9]. The Pre-Industrial (AD 1850) temperature is used as a surrogate for the Holocene time slice since we interested only in the firstorder pattern of the deglaciation. b, North Greenland Ice Core Project (NGRIP) ice-core $\delta^{18} \mathrm{O}$ data (ref. 12, black, expressed in \%o with respect to Vienna Standard Mean Ocean Water) with millennial trend (blue) and bandpass-filtered temperature $\left(0.5-1.75 \mathrm{kyr}^{-1}\right.$, red) for Holocene and LGM (grey lines in background show the full record). c, Sea surface temperature (SST) from tropical marine sediment record SO189-39KL[31], colors as in b.

extensive, containing 88 records for the Holocene and 39 for the LGM.In this case, we first derive zonal-mean estimates of temperature variability for each time slice and then form the ratio. All proxy types for which multiple calibrations exist were recalibrated using a single temperature relationship for each proxy type and region. For both the joint and the separate dataset, we quantify the variability change as the ratio of variance at timescales between 500 and 1,750 years in the spectral domain using a method that is insensitive to changes in the temporal sampling. We correct the ratio for the effects of non-climate variability in the proxy records based on independent estimates of the signal-to-noise ratio of the proxies (Methods).

All three Greenlandic ice-core records display large variability changes, with an average LGM-to-Holocene variance ratio $R=V_{\operatorname{lgm}} / V_{\text {hol }}$ of 73 (90\% confidence interval of 50-112; Fig. 2a). In contrast to this marked reduction, the area-weighted average change in variability for the rest of the globe is far lower: The separate estimate indicates a decrease in variability by a factor of 7.0 (90\% confidence interval, $2.2-16)$. The large uncertainty range is due to the combination of many different proxy records affected by potential site-specific effects such as differing seasonal responses. The magnitude of change is confirmed by the joint dataset, which offers a more precise estimate of $R=4.4$ (90\% confidence interval, 2.5-6.6) by circumventing these complications. Together, these datasets suggest 

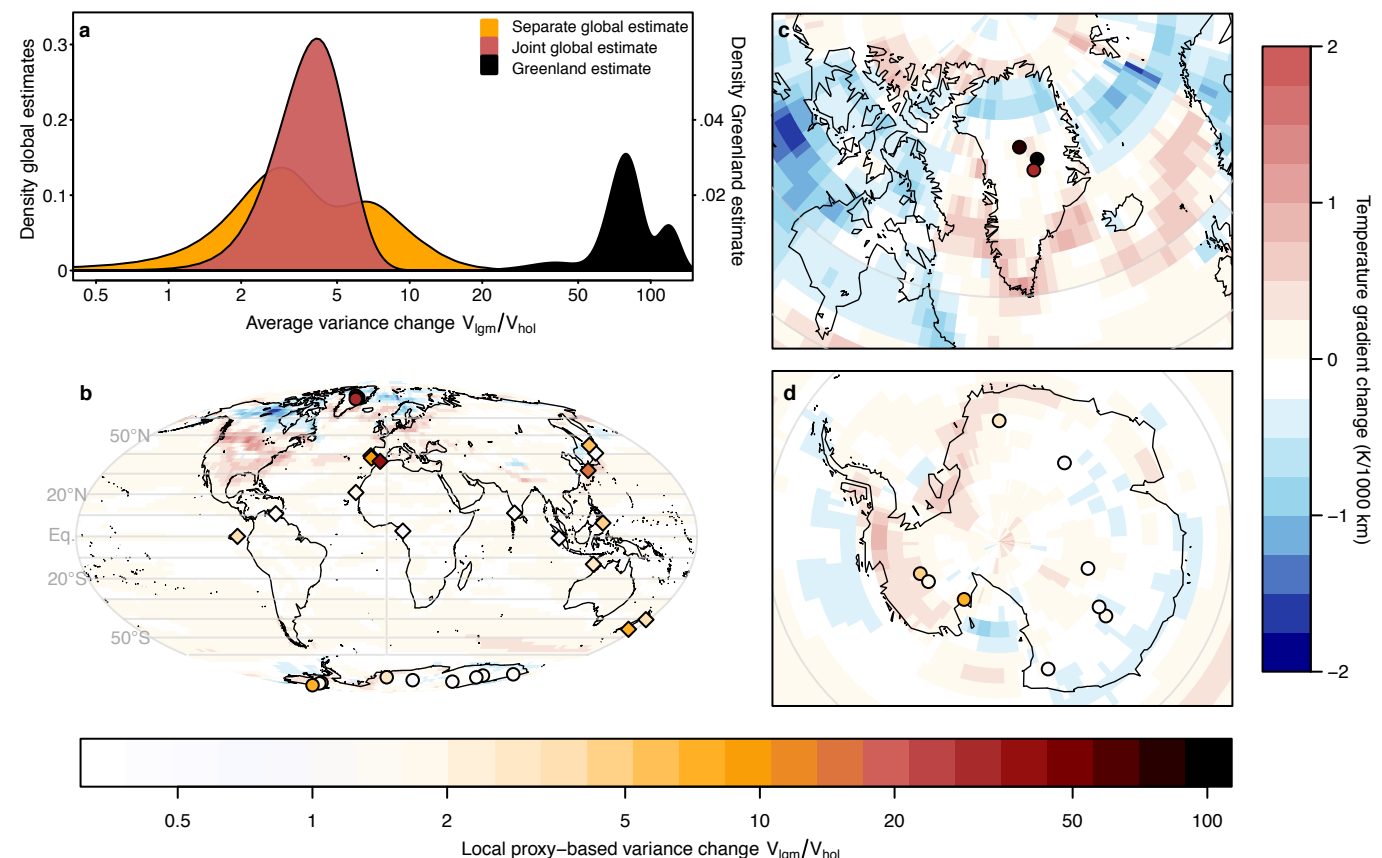

Figure 2: Global LGM-to-Holocene change in variability and temperature gradient. a, Distribution of the globally averaged area-weighted LGM-to-Holocene variance ratio (without Greenland; red denotes the joint dataset, orange the separate dataset), and the regional Greenland variance ratio (black). Note that for visibility the Greenland density estimates are on a separate y-axis. b-d, LGM-to-Holocene proxy-derived variance ratios (symbols, bottom color scale) and modelled change in temperature gradient (background; right color scale; details in Methods) for the globe (b), Greenland (c) and Antarctica (d).

a significantly lower $(p \leq 0.01)$ change in variability outside of Greenland than is found in Greenlandic ice-core records. The discrepancy also cannot be reconciled by considering a potentially lower quality of marine-based temperature reconstructions (Methods). This observation suggests that Greenlandic ice-core records should not be used as a sole reference for climate variability, particularly concerning the amplitude of change.

The spatial pattern of variability change (Fig. 2b-d) shows a distinct latitude-dependence (Fig. 3a). A small, yet statistically significant, change can be found in the tropics $\left(20^{\circ} \mathrm{S}-20^{\circ} \mathrm{N}, R=2.190 \%\right.$ confidence interval $\left.1.6-2.8\right)$. The mid-latitudes $\left(20-50^{\circ} \mathrm{S}\right.$ and $\left.20-50^{\circ} \mathrm{N}\right)$ show a moderate decrease in variability from the glacial period to the Holocene by a factor of 5.4 (90\% confidence interval, 3.3-10) and 11 (90\% confidence interval, 8.0-14). The polar regions $\left(50-90^{\circ} \mathrm{N}\right.$ and $\left.50-90^{\circ} \mathrm{S}\right)$ are only represented by Greenlandic and Antarctic ice-core records and reveal an asymmetric pattern: the Greenland change is the highest globally, whereas Antarctica displays only a small change $(R=2.5,90 \%$ confidence interval, 2.0-3.2), comparable to that in the tropical ocean. Intriguingly, West Antarctic ice cores show a stronger variability change than do ice cores from East Antarctica (Fig. 2d), a finding that is similar to the west-east contrast in the response to anthropogenic forcing[19]. The estimated pattern of variability change is similar for multicentennial and millennial timescales (Extended Data Fig. 1), showing that our finding is not limited to one specific frequency band. This result further suggests that the Dansgaard-Oeschger-event 
included in the LGM time slice has only a minor influence.

The equator-to-pole surface air temperature gradient in the LGM was larger than in the Holocene, because the high latitudes have warmed more than the tropics since the LGM[10] (Fig. 1a and 2b). Furthermore, the land--sea contrast in mid- to high latitudes was stronger in the LGM because a relatively warm open ocean contrasted with the partly ice-covered land, and changing sea-ice cover affected both the meridional and zonal temperature gradients[20]. Atmospheric temperature gradients are a primary driver for local temperature variability on synoptic timescales. Accordingly, changes of spatial gradients due to mean climate changes have been proposed to control variability changes[21, 22]. Hence, steeper temperature gradients in the LGM may have led to increased synoptic variability. Describing climate variability as the linear response to stochastic weather forcing integrated by the slow components of the climate system, such as the ocean[23], increased synoptic variability directly relates to an increase of variability on interannual to millennial timescales[24]. Contrasting the change in the atmospheric equator-topole temperature gradient - as estimated from a combined model-data temperature reconstruction[9] - with the estimated change in variability (Fig. 3b, Extended Data Fig. 2) indeed reveals a consistent pattern on a global scale (Spearman's rank correlation $r=0.43, p=0.03, \mathrm{n}=28$ ) although the high variability reconstructed for Greenland appears as an outlier (Fig. 3b). This relationship between the temperature gradient and variability change also holds for the heterogeneous pattern of temperature variability change over Antarctic land surfaces (Fig. 2d), although the quality of the gradient estimates on this regional scale is unclear. In addition, a reconfiguration of the large-scale oceanic circulation could also drive changes in temperature variability. Perturbation experiments in climate models suggest that the Atlantic Meridional Overturning Circulation (AMOC) may have been less stable in the LGM than in the Holocene[25], and the temperature response to a varying AMOC that modulates the oceanic poleward heat flux shows a first-order pattern[25] that is consistent with our estimated changes in variability (Fig. 3). However, there is no evidence that the imprint of AMOC modulations should be greater on Greenlandic air temperatures than on any other North Atlantic region.

The general meridional pattern is thus consistent with both synoptic atmospheric and oceanic contributions to the change in variability. However, neither contribution can explain the considerably stronger variability change found in the oxygen isotope records from Greenlandic ice cores, which is 18-times stronger than the global mean - a polar-to-global change in variance that is much larger than the observed polar amplification during the 20 th Century[4]. Additionally, the resultant asymmetry between Greenlandic and Antarctic variability change contrasts with the rather symmetrical polar amplification simulated by climate models for past and future climate states[26]. The specific discrepancy for the Greenlandic records thus points either to a decoupling of Greenlandic temperature 


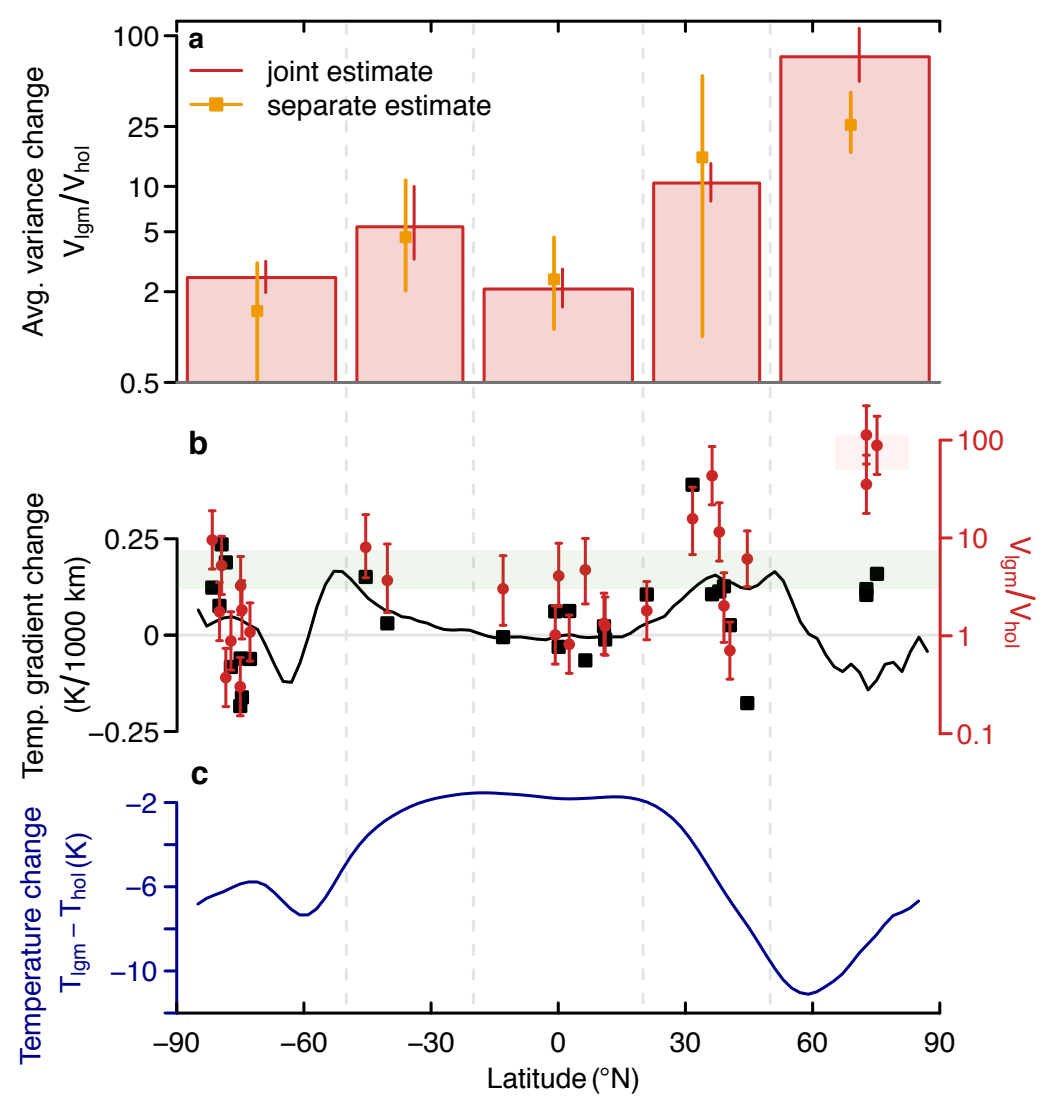

Figure 3: Latitudinal structure of LGM-to-Holocene variability and mean changes. a, Zonal mean variability change from the proxy compilations (red bars denote the joint estimate, orange points the separate estimate). $\mathbf{b}$, Latitude dependence of the equator-to-pole change in temperature gradient. The five-point smoothed zonal-mean change in gradient (black line) is shown together with the change in gradient at the proxy locations (black squares), compared to the individual proxy estimates of the change in variability (red dots). Green and red shading denotes the $90 \%$ confidence interval of the global mean variance change without Greenland and of the mean change in variance for Greenland, respectively. c, Zonal-mean change in temperature [9]. All error bars are $90 \%$ confidence intervals.

variability from global surface temperature variability, for example owing to the altitude of the ice sheet representing close to mid-tropospheric atmospheric conditions, or to strong influences on the isotopic composition of Greenlandic ice cores beyond the local site temperature.

Sea-ice changes have been linked to temperature variability changes on interannual to decadal timescales[7], and may also contribute to the uniqueness of the Greenlandic variability estimates. The sea-ice extent during the glacial period was larger than at present[20], and the increased area favored increased sea-ice variability on centennial timescales, a change that is corroborated by proxy-based sea-ice reconstructions (Extended Data Table 1). A large sea-ice lid shields more ocean heat from the atmosphere, reduces the effective heat capacity at the surface, and thus also renders local temperatures more volatile under the same forcing. Additionally, a larger sea-ice area can change more, which amplifies temperature variability on the Greenland ice sheet through atmospheric feedbacks[27]. Changes in sea-ice-extent also influence the seasonality of snow accumulation on the central Greenland ice sheet[28], 
which can strongly affect the isotopic composition recorded in ice cores [29]. Furthermore, changes in the moisture pathways as an atmospheric response to the large Northern Hemisphere ice sheets could also have caused changes in isotope variability unrelated to local temperatures[30].

On the interannual to multidecadal scale, the surface temperature variability ratio in coupled model simulations from PMIP3 confirms the overall reduction in temperature variability from the LGM to the Holocene (Methods, Extended Data Fig. 3). The spatial pattern is similar, but the magnitude of change is smaller $(R=1.28 ; 90 \%$ confidence interval, 1.25-1.30), suggesting either a difference in the partitioning of variability between fast and slow timescales, or that the models suppress long-term climate variability[17] and so do not display realistic variability changes. The tendency of coupled climate models to underestimate changes in the meridional temperature gradient[26] might also contribute to this discrepancy. To establish to what extent variability change is uniform across timescales, as predicted by linear energy balance models[23, 24], or is specific to certain timescales related to dynamic modes in the climate system, variability estimates at decadal to centennial scales are needed. Possibilities include annually laminated sediment records or a better understanding of non-climate effects on ice-core records to enable reliable high-resolution reconstructions. The PMIP3 climate model results also suggest that the temperature variability change in Greenland is not larger than elsewhere. Therefore, it is paramount to establish whether the Greenlandic variability change is indeed a change in local temperature variability or specific to the oxygen isotope proxy for temperature. The representativeness of Greenlandic isotope variability for Arctic and global temperature variability could be clarified using non-stable-water-isotope proxies for temperature in Greenland[16], more data from across the Arctic and climate modeling with embedded water-isotope tracers.

Our results have implications for the understanding of past and future climate variability. The reconstruction reveals that temperature variability decreased globally by a factor of 4 for a warming of $3-8{ }^{\circ} \mathrm{C}$ from the LGM to the Holocene. This decrease is small compared with the 73 -fold reduction estimated for Greenland, and indicates that the variability change recorded by Greenlandic ice cores is not representative of changes in variability across the globe. In terms of the magnitude of variability, these iconic datasets thus do not provide a reference for global climate changes as is often implicitly assumed. Consequently, we have to rethink the notion of an unstable glacial period and a very stable Holocene and their implications for societal evolution. Whilst a direct extrapolation from the glacial period to the future would not be prudent, it is reasonable to assume that the mean-change-tovariability-change relationship holds, given our mechanistic understanding of the drivers and the direction of future changes in the temperature gradient. Our findings therefore add support to climate modeling studies that predict a reduction in winter temperature variability under global warming via reduced spatial gradients[21, 22]. Our results 
further suggest that this variability (which dominates annual-mean temperature variability), might also translate to a reduction of multidecadal and slower variability[7]. More high-resolution records of glacial climate, continued quantification of recording and preserving processes of palaeoclimate signals, and an extension of similar analyses to other climate states will help to further constrain the mean-state dependency of climate variability.

\section{References}

[1] Katz, R. W. \& Brown, B. G. Extreme events in a changing climate: Variability is more important than averages. Clim. Change 21, 289-302 (1992)

[2] Ditlevsen, P. D., Svensmark, H. \& Johnsen, S. Contrasting atmospheric and climate dynamics of the last-glacial and Holocene periods. Nature 379, 810-812 (1996)

[3] Shao, Z.-G. \& Ditlevsen, P. D. Contrasting scaling properties of interglacial and glacial climates. Nat. Commun. 7, 10951 (2016)

[4] IPCC, 2013. Climate Change 2013: The Physical Science Basis. Contribution of Working Group I to the Fifth Assessment Report of the Intergovernmental Panel on Climate Change (Cambridge University Press, 2013)

[5] Hansen, J., Sato, M. \& Ruedy, R. Perception of climate change. Proc. Natl. Acad. Sci. U.S.A. 109, E2415E2423 (2012)

[6] Rhines, A. \& Huybers, P. Frequent summer temperature extremes reflect changes in the mean, not the variance. Proc. Natl. Acad. Sci. U.S.A. 110, E546 (2013)

[7] Huntingford, C., Jones, P. D., Livina, V. N., Lenton, T. M. \& Cox, P. M. No increase in global temperature variability despite changing regional patterns. Nature 500, 327-330 (2013)

[8] Shakun, J. D. \& Carlson, A. E. A global perspective on Last Glacial Maximum to Holocene climate change. Quat. Sci. Rev. 29, 1801-1816 (2010)

[9] Annan, J. D. \& Hargreaves, J. C. A new global reconstruction of temperature changes at the Last Glacial Maximum. Clim. Past 9, 367-376 (2013)

[10] MARGO Project Members. Constraints on the magnitude and patterns of ocean cooling at the Last Glacial Maximum. Nat. Geosci. 2, 127-132 (2009) 
[11] Koutavas, A. \& Joanides, S. El Niño-Southern Oscillation extrema in the Holocene and Last Glacial Maximum. Paleoceanography 27, PA4208 (2012)

[12] NGRIP members. High-resolution record of Northern Hemisphere climate extending into the last interglacial period. Nature 431, 147-151 (2004)

[13] Masson-Delmotte, V. et al. GRIP Deuterium Excess Reveals Rapid and Orbital-Scale Changes in Greenland Moisture Origin. Science 309, 118-21 (2005)

[14] Gamble, C., Davies, W., Pettitt, P. B. \& Richards, M. Climate change and evolving human diversity in Europe during the last glacial. Phil. Trans. R. Soc. Lond. B Biol. Sci. 359, 243-254 (2004)

[15] Richerson, P. J., Boyd, R. \& Bettinger, R. L. Was Agriculture Impossible during the Pleistocene but Mandatory during the Holocene? A Climate Change Hypothesis. Am. Antiq. 66, 387-411 (2001)

[16] Kobashi, T. et al. High variability of Greenland surface temperature over the past 4000 years estimated from trapped air in an ice core. Geophys. Res. Lett. 38, L21501 (2011)

[17] Laepple, T. \& Huybers, P. Ocean surface temperature variability: Large model-data differences at decadal and longer periods. Proc. Natl. Acad. Sci. U.S.A. (2014)

[18] Jouzel, J. et al. Validity of the temperature reconstruction from water isotopes in ice cores. J. Geophys. Res. 102, 26471-26487 (1997)

[19] Bromwich, D. H. et al. Central West Antarctica among the most rapidly warming regions on Earth. Nat. Geosci. 6, 139-145 (2012)

[20] de Vernal, A. et al. Comparing proxies for the reconstruction of LGM sea-surface conditions in the northern North Atlantic. Quat. Sci. Rev. 25, 2820-2834 (2006)

[21] Schneider, T., Bischoff, T. \& Płotka, H. Physics of Changes in Synoptic Midlatitude Temperature Variability. J. Clim. 28, 2312-2331 (2015)

[22] Holmes, C. R., Woollings, T., Hawkins, E. \& de Vries, H. Robust Future Changes in Temperature Variability under Greenhouse Gas Forcing and the Relationship with Thermal Advection. J. Clim. 29, 2221-2236 (2016)

[23] Hasselmann, K. Stochastic climate models Part I. Theory. Tellus 28, 473-485 (1976) 
[24] Rypdal, K., Rypdal, M. \& Fredriksen, H.-B. Spatiotemporal Long-Range Persistence in Earth's Temperature Field: Analysis of Stochastic-Diffusive Energy Balance Models. J. Clim. 28, 8379-8395 (2015)

[25] Sévellec, F. \& Fedorov, A. V. Unstable AMOC during glacial intervals and millennial variability: The role of mean sea ice extent. Earth Planet. Sci. Lett. 429, 60-68 (2015)

[26] Masson-Delmotte, V. et al. Past and future polar amplification of climate change: climate model intercomparisons and ice-core constraints. Clim. Dyn. 26, 513-529 (2006)

[27] Li, C., Battisti, D. S., Schrag, D. P. \& Tziperman, E. Abrupt climate shifts in Greenland due to displacements of the sea ice edge. Geophys. Res. Lett. 32, L19702 (2005)

[28] Rhines, A. \& Huybers, P. J. Sea Ice and Dynamical Controls on Preindustrial and Last Glacial Maximum Accumulation in Central Greenland. J. Clim. 27, 8902-8917 (2014)

[29] Laepple, T., Werner, M. \& Lohmann, G. Synchronicity of Antarctic temperatures and local solar insolation on orbital timescales. Nature 471, 91-94 (2011)

[30] Wunsch, C. Abrupt climate change: An alternative view. Quat. Res. 65, 191-203 (2006)

[31] Mohtadi, M. et al. North Atlantic forcing of tropical Indian Ocean climate. Nature 509, 76-80 (2014)

\section{Methods}

\section{Proxy data for variability estimates.}

For the variability analyses we collected all available proxy records for temperature that fulfilled the following sampling criteria. To be included, a record had (1) to be associated with an established, published calibration to temperature and (2) cover at least $4 \mathrm{kyr}$ in the interval of the Holocene (8-0 kyr ago) and/or the LGM (27-19 kyr ago) at (3) a mean sampling frequency of $1 / 225 \mathrm{yr}^{-1}$ or higher. Our definition for the LGM time slice, based on previously published starting[32] and end[10] times, covers the coldest part of the last Glacial with the most stable boundary conditions while maintaining the same period duration as for the Holocene section. All proxy time series which fulfil the sampling criteria for both time intervals are included in our primary 'joint' dataset. All time series which fulfil the criteria only for one of the two intervals are included only for this period ('separate' dataset). This dataset consequently also includes all records from the joint dataset. All selected records are listed in the Supplementary Information along with the time intervals for which they were included. Extended Data Table 2 summarizes the individual variance ratio estimates for the joint dataset. 


\section{Model-based estimates for the temperature gradient and variability change.}

Changes in temperature gradient between the LGM and the Holocene were estimated based on the LGM-topre-industrial temperature anomaly[9], which is based on proxy and model data from the Paleoclimate Model Intercomparison Project Phase 2 (PMIP2). The equator-to-pole temperature gradient change was calculated from the temperature anomaly differences between adjacent gridboxes in poleward direction (north relative to south), divided by the meridional gridbox extent $(222 \mathrm{~km})$ and normalized to $1000 \mathrm{~km}$. The model-based LGMto-Holocene variability change estimate was derived from surface $(2 \mathrm{~m})$ air temperature output for the LGM and pre-industrial simulations available through the Paleoclimate Model Intercomparison Project Phase 3 (PMIP3CMIP5) archives. Model simulations were included from the CCSM4, CNRM-CM5, FGOALS-g2, GISS-E2-R, IPSL-CM5A-LR, MIROC-ESM, MPI-ESM-P and MRI-CGCM3 models. For each model, the last 100 years of the archived simulations were used to estimate temperature variance fields. The fields of the ratio of variances were then regridded to a common T63 resolution to form model-mean ratio of variances (Extended Data Fig. 3). We use the pre-industrial model results as a reasonable surrogate for the Holocene time slice since we are interested in the first-order patterns of the gradient and variability changes, which are governed by the deglaciation.

\section{Temperature recalibration of proxy records.}

Marine and ice-core records were recalibrated using a single temperature relationship for each proxy type and region to minimize the calibration-dependent uncertainty for variability estimates based on the separate dataset. Terrestrial records based on lacustrine sediments, pollen and tree were not recalibrated due to the lack of a suitable global calibration for these proxy types.

Recalibration of ice-core records. For the calibration of ice-core stable isotope data to temperature (isotope-totemperature slope in ${ }^{\circ} \mathrm{C} \%{ }^{-1}$ ) two distinct methods exist: based on either the relationship of observed present-day spatial gradients in surface snow isotopic composition and temperature (spatial slope) or on temporal gradients observed at a single site (temporal slope).

For Greenland, temporal slopes appear to lie consistently above the spatial slope, depending on the timescale, most likely due to changes in moisture origin and seasonality of precipitation[18]. For the Holocene temporal slope we used a borehole temperature calibration[33] of $2.1^{\circ} \mathrm{C} \%{ }^{-1}$ with an estimated uncertainty of $\pm 0.4^{\circ} \mathrm{C} \%{ }^{-1}$ based on the slopes reported by other studies[34, 35, 36, 37, 38, 39]. The LGM temporal slope is a factor of $1-2$ above the Holocene slope[40, 38, 41, 37, 42]; as a best guess we used a factor of 1.5. 
For Antarctica, direct estimations of temporal slopes are difficult. However, the difference between spatial and temporal slopes as well as the timescale dependency of the latter is expected to be small[43]. Here, we adopted reported spatial slopes[44] of $1.25{ }^{\circ} \mathrm{C} \%^{-1}$ for $\delta^{18} \mathrm{O}$ and $0.16{ }^{\circ} \mathrm{C} \%^{-1}$ for $\delta^{2} \mathrm{H}$ with an uncertainty of $20 \%$ for recalibrating the Antarctic ice-core data.

For tropical ice cores, we adopted a constant calibration slope for $\delta^{18} \mathrm{O}$ of $1.49^{\circ} \mathrm{C} \%^{-1}$ [45].

Recalibration of marine records. Marine proxy records were recalibrated if the proxy type occurs more than once in our data collection and a suitable global calibration existed. Most of the $\mathrm{Mg} / \mathrm{Ca}$ records in our compilation are based on planktic foraminifera Globigerinoides ruber, converted to temperatures using the calibration $[46](\mathrm{Mg} / \mathrm{Ca}=$ $b \cdot \exp (a \cdot \mathrm{SST}), a=0.09(\mathrm{mmol} / \mathrm{mol}){ }^{\circ} \mathrm{C}^{-1}, b=0.38 \mathrm{mmol} / \mathrm{mol}$, standard errors $s_{a}=0.003\left(\mathrm{mmol} / \mathrm{mol}^{\circ}{ }^{\circ} \mathrm{C}^{-1}, s_{b}=\right.$ $0.02 \mathrm{mmol} / \mathrm{mol}$ ). For consistency, we recalibrated other $G$. ruber $\mathrm{Mg} / \mathrm{Ca}$ records to the same calibration even though it is established using sediment trap samples and hence not a global calibration. For species other than G. ruber, i.e./ Globigerinoides bulloides (two records from different regions) and Neogloboquadrina pachyderma (left-coiling; one record), we kept the $\mathrm{Mg} / \mathrm{Ca}$ records as published. Similarly, temperature records based on the transfer function of diatom, radiolarian and foraminifera assemblages were also kept as published. All UK'37-based records were recalibrated using the calibration $[47]\left(\mathrm{UK}^{\prime} 37=a \cdot \mathrm{SST}+b, a=0.033^{\circ} \mathrm{C}^{-1}, b=0.044, s_{a}=0.001^{\circ} \mathrm{C}^{-1}, s_{b}=0.016\right)$. All $\mathrm{TEX}_{86}$ and $\mathrm{TEX}_{86}^{\mathrm{H}}$ records were recalibrated to the subsurface $\mathrm{TEX}_{86}^{\mathrm{H}}$ calibration[48] $\left(T=a \cdot \mathrm{TEX}_{86}^{\mathrm{H}}+b\right.$, $a=40.8^{\circ} \mathrm{C}, b=22.3^{\circ} \mathrm{C}, s_{a}=4.37^{\circ} \mathrm{C}, s_{b}=2.19^{\circ} \mathrm{C}$ ) as marine surface and subsurface temperature variability are on average similar[48].

\section{Timescale-dependent variance and variance ratio estimation.}

The records were interpolated onto a regular time axis given by their individual mean sampling frequency in the LGM or the Holocene, following a previously reported procedure[17]. To minimize aliasing, data were first linearly interpolated to ten times the target resolution, low-pass filtered using a finite response filter with a cutoff frequency of 1.2 divided by the target time step, and then resampled at the target resolution. Linear interpolation of a process that has been unevenly sampled reduces the variance near the Nyquist frequency, but the sampling rate of our records relative to the timescale of the variance estimates is high enough to minimize this effect (Extended Data Fig. 4). Timescale-dependent variance estimates were obtained by integrating the raw periodogram[49] in the frequency band $\left(f_{1}, f_{2}\right)$ using $f_{1}=1 / 500 \mathrm{yr}^{-1}$ and $f_{2}=1 / 1,750 \mathrm{yr}^{-1}$ to capture multicentennial- to millennialscale temperature variability. All spectra are shown in Extended Data Fig. 4. Tests with surrogate records on the original time axes showed that our estimates are largely unbiased (Extended Data Fig. 5). Furthermore, our 
results are robust under changes of the sampling criteria (Extended Data Fig. 1).

Confidence intervals for the variance estimates were derived from the $\chi^{2}$-distribution with $d$ degrees of freedom, in which $d$ is given by twice the number of spectral power estimates in the frequency band $\left(f_{1}, f_{2}\right)$. Confidence intervals for variance ratios were derived accordingly from the $F$-distribution with the degrees of freedom of the variance estimates.

For the joint dataset, zonally averaged variance ratios were derived from the bias-corrected individual ratio

estimates as $\bar{R}=\frac{1}{N} \sum_{i=1}^{N} \frac{d_{\mathrm{hol}, i}-2}{d_{\mathrm{hol}, i}} R_{i}$ where $R_{i}=\frac{V_{\mathrm{lgm}, i}}{V_{\mathrm{hol}, i}}$ is the noise-corrected variance ratio of the $i$-th record. For the separate dataset, zonally averaged variance ratios were derived from the ratio of the zonal-mean variances with subsequent noise correction.

For both data sets, global mean variance ratios were derived from the area-weighted zonal means. To obtain the ratio distributions (Fig. 2a) we sample 50,000 times with replacement from the proxy estimates (joint: ratios, separate: variances). For each realization, we form the zonal-mean estimates of the variance change (for the joint dataset), or of the mean Holocene and LGM variance and then take the ratio (for the separate dataset). We then form the area-weighted global mean for the variance change. Confidence intervals for the global-mean estimate are derived as quantiles from the realizations. The ratio distribution for Greenland is estimated using the same method but only considering the three Greenlandic ice cores. Kernel density estimates are shown (Fig. 2a) using a Gaussian smoothing kernel with a bandwidth of $1 / 10$ of the mean ratio, so 0.4 for the global mean and 7 for Greenland.

\section{Noise correction}

We derive the impact of noise on the estimated variance ratio $R^{\prime}$ between two climate periods,

$$
R^{\prime}:=\frac{\operatorname{var}\left(X_{1}\right)}{\operatorname{var}\left(X_{0}\right)}
$$

Here, $X_{1}$ and $X_{2}$ stand for the proxy time series of the investigated (LGM) and the reference climate period (Holocene), respectively. Each proxy time series contains noise. Assuming additive noise, and that the climate signal and noise are uncorrelated on each timescale covered, we can split the variances in equation (1) into contributions from the signal $S$ and the noise $\varepsilon$,

$$
R^{\prime}=\frac{\operatorname{var}\left(S_{1}\right)+\operatorname{var}\left(\varepsilon_{1}\right)}{\operatorname{var}\left(S_{0}\right)+\operatorname{var}\left(\varepsilon_{0}\right)}=\frac{\operatorname{var}\left(S_{1}\right)}{\operatorname{var}\left(S_{0}\right)\left[1+\mathrm{SNR}^{-1}\right]}+\frac{\operatorname{var}\left(\varepsilon_{1}\right)}{\operatorname{var}\left(S_{0}\right)\left[1+\mathrm{SNR}^{-1}\right]},
$$

in which we have introduced the reference-period signal-to-noise variance ratio, SNR $:=\operatorname{var}\left(S_{0}\right) / \operatorname{var}\left(\varepsilon_{0}\right)$. Identifying the true climate variance ratio, $R=\operatorname{var}\left(S_{1}\right) / \operatorname{var}\left(S_{0}\right)$, and denoting the noise variance ratio by $F_{\varepsilon}=$ 
$\operatorname{var}\left(\varepsilon_{1}\right) / \operatorname{var}\left(\varepsilon_{0}\right)$, we obtain

$$
R^{\prime}=\frac{\mathrm{SNR}}{1+\mathrm{SNR}} R+\frac{F_{\varepsilon}}{1+\mathrm{SNR}}
$$

Solving for $R$ yields

$$
R=R^{\prime} \frac{1+\mathrm{SNR}}{\mathrm{SNR}}-\frac{F_{\varepsilon}}{\mathrm{SNR}}
$$

Because $R$ cannot be negative, the parameters must always satisfy the condition $F_{\varepsilon} /(1+\mathrm{SNR}) \leq R^{\prime}$. For any $R^{\prime} \geq F_{\varepsilon}$, the effect of noise dampens the true ratio ( $R \geq R^{\prime}$, Extended Data Fig. 6a).

To correct for the effect of noise on the LGM-to-Holocene variance ratio, we apply equation (4) both to every individual variance ratio estimated for the joint dataset and to the zonal-mean variance ratios derived from the separate dataset. A reasonable assumption is that the noise level is independent of the climate period, $F_{\varepsilon}=1$, which we adopted for all analyses. For the joint dataset, we assumed a signal-to-noise ratio of 1.5 for the Greenland records and of 1 for all other records. For correcting the zonal-mean variance ratios derived from the separate dataset we adopted a signal-to-noise ratio of 1.

Testing the impact of the noise correction on the variability change difference. The signal-to-noise ratio is a considerable source of uncertainty for the noise correction. Signal-to-noise ratio values can be estimated, amongst other approaches, by direct forward modeling of the proxy[17], or by correlation of nearby records[50, 51, 17, 52]. An overview over signal-to-noise ratios for the regions and proxies of interest are given in Extended Data Fig. 6c. We tested the impact of the noise correction on the difference between the Greenland ice-core-based variance ratio estimates with those from the proxy records outside Greenland. To bring the variance ratios into agreement, the signal-to-noise ratio of proxies outside Greenland would have to be less than 0.05 (Extended Data Fig. 6b), which is one order of magnitude below published estimates for marine proxy[17] and Antarctic isotope records[52]. It is therefore unlikely that the observed variability difference can be attributed to Greenland ice cores being better recorders (that is, having a higher signal-to-noise ratio) than marine sediment or Antarctic ice-core records.

\section{Potential effect of ecological adaption and bioturbational mixing on marine variance ratios.}

Variability derived from biological proxies, that is, recorded by marine organisms, are possibly muted relative to the actual environmental changes due to the tendency of organisms towards adapting and seeking their ecological niche (for example, of a certain temperature or nutrient range)[53]. Our results are based on the ratio of variability and not on absolute variability estimates. Therefore, for ecological adaptation to affect our results, LGM variability needs to be muted to a much larger extent than that for the Holocene. In the simple conceptual ecological 
model[53], given the same temperature preference, larger variability would result in a stronger damping. However, the largest part of the variability seen by marine organisms is the seasonal and vertical temperature range in the depth habitat. This spread is controlled by insolation and stratification and not primarily by the climate state. The interannual to millennial variability, that we find to be larger in the LGM, contributes only a small fraction to the total variability and so should not be a primary control of the damping strength affecting the proxy records. Our oceanic temperature variability estimates for the joint dataset (i.e. containing both Holocene and LGM) are based on alkenone-based UK'37 (eight sites) and the $\mathrm{Mg} / \mathrm{Ca}$ of planktic foraminifera G. ruber (seven sites), the latter from tropical sites. Unlike planktic foraminifera, which have their preferred temperature niche, the known major producers of alkenones such as the coccolithophore Emiliana huxleyi occur throughout the global ocean from the tropics to the polar waters. Their abundance is mostly controlled by nutrient and light availability, which do not always covary with temperature. Most of our G. ruber $\mathrm{Mg} / \mathrm{Ca}$ records are from the tropics, with Holocene temperatures (e.g., $29^{\circ} \mathrm{C}$ at SO189-39KL; Fig. 1c) close to the warm end of their temperature niche $\left(15-29^{\circ} \mathrm{C}\right.$, ref.[54]) whereas LGM temperatures (e.g., $26^{\circ} \mathrm{C}$ at SO189-39KL; Fig. 1c) are closer to the mean of the range. Therefore, if there is ecological adaptation, it is more likely to occur near the extremes (i.e. the Holocene) rather than in the middle of the range. This would in fact result in an amplified variance ratio between Holocene and LGM.

Bioturbational mixing in marine sediments reduces the absolute variability preserved in marine sediments[55]. However, here we focus our analysis on variability changes and thus largely circumvent this problem, because both the glacial and the Holocene part of the core are affected by bioturbation. Bioturbation can be approximated as a linear filter[55] and therefore the ratio of variances is not affected as long as the sedimentation rate and bioturbation strength that define the filter are similar in both time periods periods or do not change systematically between climate states. Our dataset shows no evidence for a systematic change in sedimentation rate with seven of the 16 marine cores in our joint dataset showing higher and nine lower sedimentation rates in the Holocene (with a statistically insignificant change in mean sedimentation rate of $20 \%$ ). The changes also show no detectable latitudinal dependency. There is also no evidence for a systematic change in largely unconstrained bioturbation strength between the time periods in the manuscripts describing the datasets.

Despite not being effects of climate, the ecological preference of the organisms that record the climate signal and bioturbational mixing of the sediment can affect variability estimates and may thus add to site-specific variability changes. But the aforementioned arguments show that their effect is expected to be very small compared to the orders of magnitude difference between tropics and mid-latitudes and between marine cores and ice cores. 


\section{Testing the impact of the proxy sampling locations on zonal-mean variance estimates.}

The proxy locations are not randomly distributed in space, which could lead to sampling biases. To test for a potential sampling bias we analyse the 2-metre temperature field of the last 7,000 years from the coupled atmosphere ocean TraCE-21K simulation[56]. The time period is chosen to focus on the continuum of climate variability and to minimize the effect of the deglaciation. The temperature variance field for centennial and longer timescales is derived by estimating the variance at every gridpoint after applying a low-pass finite response filter with a cut-off frequency of $1 / 100 \mathrm{yr}^{-1}$.

We sample the variance field at the actual proxy locations and average the results into the same latitude bands as for the proxy-based variance ratio estimates. To estimate the expected distribution of mean values from unbiased locations, we sample $N$ random locations at each latitude band where $N$ corresponds to the number of actual records in each band. We form the mean of this random sample, and repeat the procedure 10,000 times from which we report the $90 \%$ quantiles. The results (Extended Data Fig. 7) show that the mean values from the actual proxy locations are always inside the expected distribution. This result holds when using the full dataset as well as when restricting the analysis to the records which cover both the LGM and the Holocene.

Acknowledgements This study was supported by the Initiative and Networking Fund of the Helmholtz Association grant no. VG-900NH. KR acknowledges funding by the German Science Foundation (DFG, code RE 3994/11). This project has received funding from the European Research Council (ERC) under the European Union's Horizon 2020 research and innovation programme (grant agreement no. 716092). Peter Huybers, Louise Sime, Max Holloway and Torben Kunz are acknowledged for helpful comments on the manuscript. We thank all original data contributors who made their proxy data available, and acknowledge the World Climate Research Programme's Working Group on Coupled Modeling, which is responsible for CMIP, and thank the climate modeling groups for producing and making available their model output. The US Department of Energy's Programme for Climate Model Diagnosis and Intercomparison provided coordinating support for CMIP5 and led development of software infrastructure in partnership with the Global Organization for Earth System Science Portals. The PMIP3 Data archives are supported by CEA and CNRS.

Code availability Code is available on request from the authors.

Data availability The authors declare that all data supporting the findings of this study are available within the paper, given references, or in the supplementary information files. Source data for Figures 2 and 3 are provided with the paper. 
Author Contributions K.R. and T.L. designed the research; T.M. established the ice database and signal-tonoise ratio correction. S.L.H. established the marine database. K.R. and T.L. developed the methodology. K.R. performed the data analysis and wrote the first draft of the manuscript. K.R., T.M., S.L.H., and T.L. contributed to the interpretation and the preparation of the final manuscript.

Author Information Reprints and permissions information is available at www.nature.com/reprints. The authors declare that they have no competing financial interests. Correspondence and requests for materials should be addressed to K.R. (krehfeld@awi.de).

\section{Method references}

[32] Rasmussen, S. O. et al. Synchronization of the NGRIP, GRIP, and GISP2 ice cores across MIS 2 and palaeoclimatic implications. Quat. Sci. Rev. 27, 18-28 (2008)

[33] Vinther, B. M. et al. Holocene thinning of the Greenland ice sheet. Nature 461, 385-388 (2009)

[34] Shuman, C. A. et al. Temperature and accumulation at the Greenland Summit: Comparison of high-resolution isotope profiles and satellite passive microwave brightness temperature trends. J. Geophys. Res. 100, 9165$9177(1995)$

[35] Beltrami, H. \& Taylor, A. E. Records of climatic change in the Canadian Arctic: towards calibrating oxygen isotope data with geothermal data. Glob. Planet. Change 11, 127-138 (1995)

[36] Cuffey, K. M., Alley, R. B., Grootes, P. M., Bolzan, J. M. \& Anandakrishnan, S. Calibration of the $\delta^{18} \mathrm{O}$ isotopic paleothermometer for central Greenland, using borehole temperatures. J. Glaciol. 40, 341-349 (1994)

[37] Cuffey, K. M. \& Clow, G. D. Temperature, accumulation, and ice sheet elevation in central Greenland through the last deglacial transition. J. Geophys. Res. 102, 26383-26396 (1997)

[38] Johnsen, S. J. et al. The $\delta^{18} \mathrm{O}$ record along the Greenland Ice Core Project deep ice core and the problem of possible Eemian climatic instability. J. Geophys. Res. 102, 26397-26410 (1997)

[39] Sjolte, J. et al. Modeling the water isotopes in Greenland precipitation 1959-2001 with the meso-scale model REMO-iso. J. Geophys. Res. 116, D18105 (2011)

[40] Johnsen, S. J., Dahl-Jensen, D., Dansgaard, W. \& Gundestrup, N. Greenland palaeotemperatures derived from GRIP bore hole temperature and ice core isotope profiles. Tellus B 47, 624-629 (1995) 
[41] Cuffey, K. M. et al. Large Arctic Temperature Change at the Wisconsin-Holocene Glacial Transition. Science 270, 455-458 (1995)

[42] Kindler, P. et al. Temperature reconstruction from 10 to $120 \mathrm{kyr}$ b2k from the NGRIP ice core. Clim. Past 10, 887-902 (2014)

[43] Jouzel, J. Magnitude of isotope/temperature scaling for interpretation of central Antarctic ice cores. J. Geophys. Res. 108, 4361 (2003)

[44] Masson-Delmotte, V. et al. A Review of Antarctic Surface Snow Isotopic Composition: Observations, Atmospheric Circulation, and Isotopic Modeling. J. Clim. 21, 3359-3387 (2008)

[45] Thompson, L. G. et al. Late Glacial Stage and Holocene Tropical Ice Core Records from Huascarán, Peru. Science 269, 46-50 (1995)

[46] Anand, P., Elderfield, H. \& Conte, M. H. Calibration of Mg/Ca thermometry in planktonic foraminifera from a sediment trap time series. Paleoceanography 18, 1050 (2003)

[47] Müller, P. J., Kirst, G., Ruhland, G., von Storch, I. \& Rosell-Melé, A. Calibration of the alkenone paleotemperature index $\mathrm{U}_{37}^{\mathrm{K}}$ based on core-tops from the eastern South Atlantic and the global ocean $\left(60^{\circ} \mathrm{N}-60^{\circ} \mathrm{S}\right)$. Geochim. Cosmochim. Acta 62, 1757-1772 (1998)

[48] Ho, S. L. \& Laepple, T. Flat meridional temperature gradient in the early Eocene in the subsurface rather than surface ocean. Nat. Geosci. 9, 606-610 (2016)

[49] Chatfield, C. The Analysis of Time Series: An Introduction (Chapman \& Hall/CRC, Boca Raton, Florida, 2004), 6th edn.

[50] Fisher, D., Reeh, N. \& Clausen, H. Stratigraphic Noise in Time Series Derived from Ice Cores. Ann. Glaciol. 6, 76-83 (1985)

[51] Steen-Larsen, H. C. et al. Understanding the climatic signal in the water stable isotope records from the NEEM shallow firn/ice cores in northwest Greenland. J. Geophys. Res. 116, D06108 (2011)

[52] Münch, T., Kipfstuhl, S., Freitag, J., Meyer, H. \& Laepple, T. Constraints on post-depositional isotope modifications in East Antarctic firn from analysing temporal changes of isotope profiles. The Cryosphere 11, 2175-2188 (2017) 
[53] Mix, A. The oxygen-isotope record of glaciation. In North America and adjacent oceans during the last deglaciation, 111-135 (Geological Society of America, Boulder, Colorado, 1987)

[54] Hilbrecht, H. Extant Planktic Foraminifera and the Physical Environment in the Atlantic and Indian Oceans: An atlas based on CLIMAP and Levitus (1982) data. Tech. Rep., Eidgenössische Technische Hochschule und Universität Zürich, Zürich (1996)

[55] Berger, W. H. \& Heath, G. R. Vertical mixing in pelagic sediments. J. Mar. Res. 26, 134-143 (1968)

[56] Liu, Z. et al. Transient Simulation of Last Deglaciation with a New Mechanism for Bølling-Allerød Warming. Science 325, 310-314 (2009)

[57] Müller, J. \& Stein, R. High-resolution record of late glacial and deglacial sea ice changes in Fram Strait corroborates ice-ocean interactions during abrupt climate shifts. Earth Planet. Sci. Lett. 403, 446-455 (2014)

[58] Hoff, U., Rasmussen, T. L., Stein, R., Ezat, M. M. \& Fahl, K. Sea ice and millennial-scale climate variability in the Nordic seas $90 \mathrm{kyr}$ ago to present. Nat. Commun. 7, 12247 (2016)

[59] Veres, D. et al. The Antarctic ice core chronology (AICC2012): an optimized multi-parameter and multi-site dating approach for the last 120 thousand years. Clim. Past 9, 1733-1748 (2013)

[60] Johnsen, S. J. et al. A "deep" ice core from East Greenland. Meddelelser om Grønland: Geoscience (Kommissionen for Videnskabelige Undersøgelser i Grønland, 1992)

[61] Seierstad, I. K. et al. Consistently dated records from the Greenland GRIP, GISP2 and NGRIP ice cores for the past $104 \mathrm{ka}$ reveal regional millennial-scale $\delta^{18} \mathrm{O}$ gradients with possible Heinrich event imprint. Quat. Sci. Rev. 106, 29-46 (2014)

[62] Grootes, P. M., Stuiver, M., White, J. W. C., Johnsen, S. \& Jouzel, J. Comparison of oxygen isotope records from the GISP2 and GRIP Greenland ice cores. Nature 366, 552-554 (1993).

[63] Grootes, P. M. \& Stuiver, M. Oxygen 18/16 variability in Greenland snow and ice with $10^{3}$ - to $10^{5}$-year time resolution. J. Geophys. Res. 102, 26455-26470 (1997)

[64] Stuiver, M. \& Grootes, P. M. GISP2 Oxygen Isotope Ratios. Quat. Res. 53, 277-284 (2000) 


\section{Extended Data figures (EDF)}
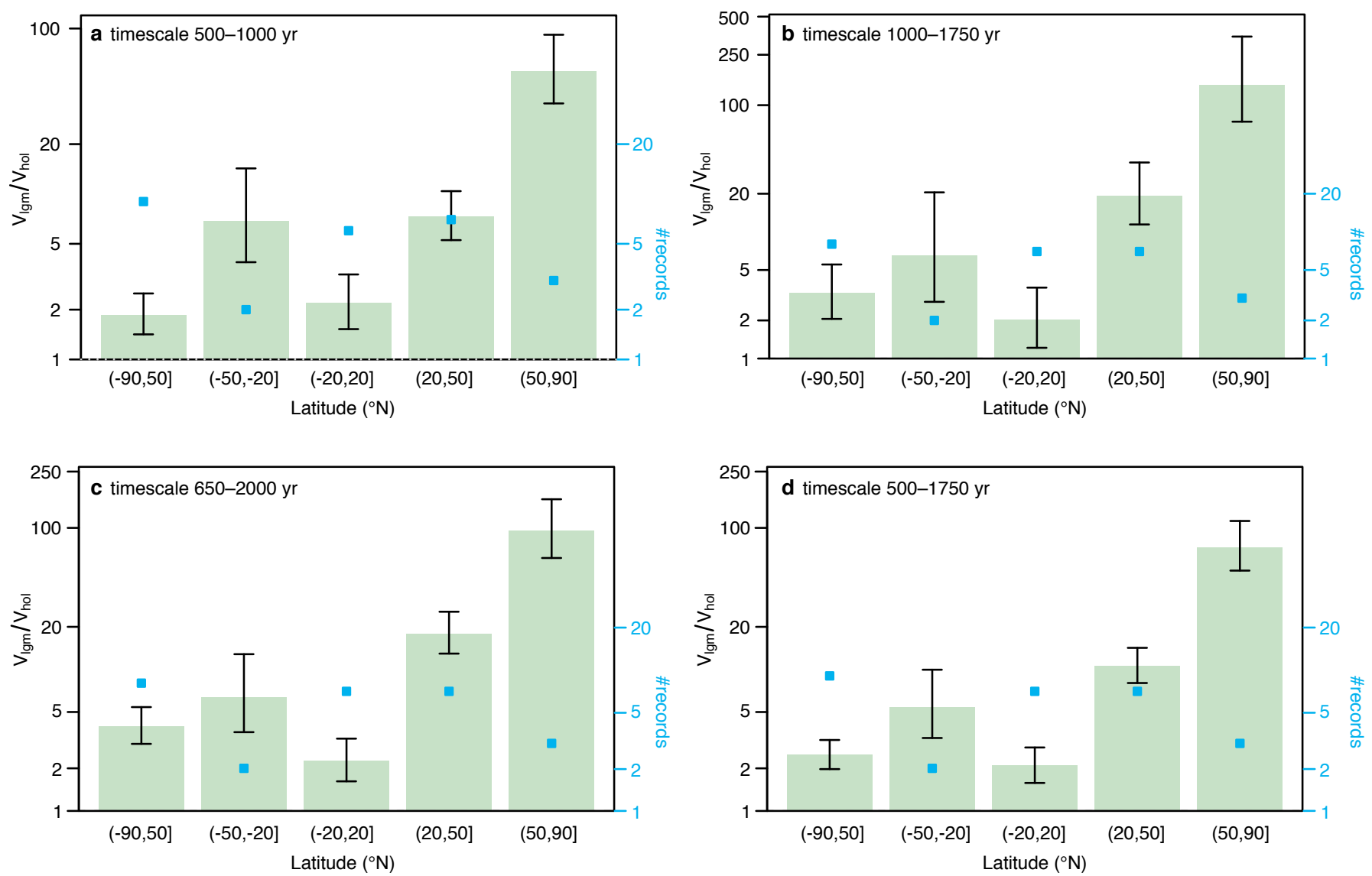

EDF 1: Zonal variability change pattern for different timescales and length requirements. a-d, Results for the estimated zonal-mean variance ratios based on the joint dataset are shown as a function of the considered timescale and the minimum number of data points in the time period window: 500-1000-year timescale with a minimum of 25 data points (a); 1000-1750-year timescale with a minimum of 25 data points (b); 650-2000-year timescale with a minimum of 20 data points (c); 500-1750-year timescale with a minimum of 25 data points (d) which corresponds to the results shown in the main text. The number of records for each zonal-mean ratio is indicated by blue points. The total number of records varies depending on the timescale constraints. Error bars denote the $90 \%$ confidence intervals of the zonal mean. 


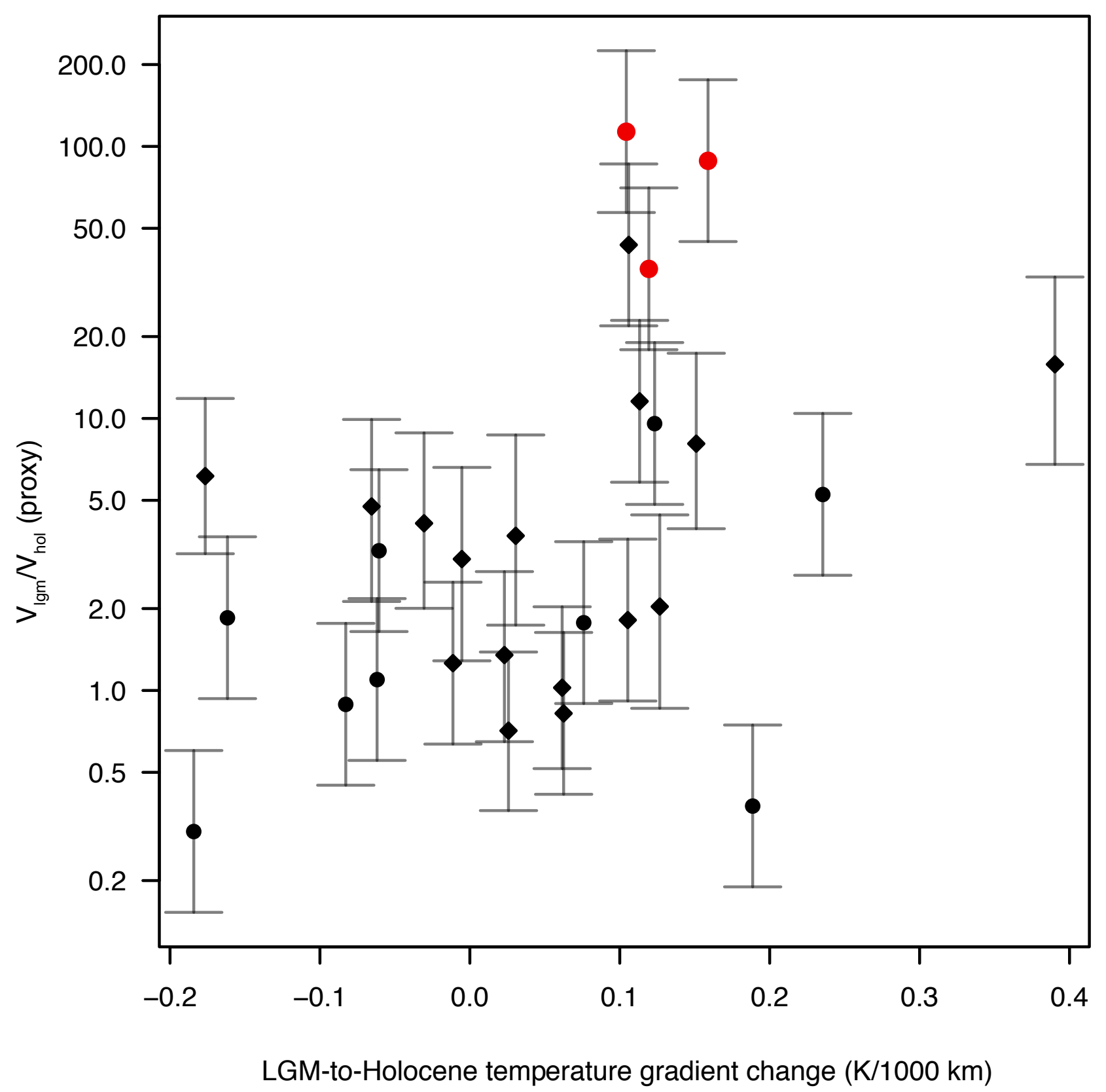

EDF 2: Temperature gradient versus variability change. Scatter plot of the model-based equator-to-pole temperature gradient change at the proxy locations versus the variability change estimated from the proxy records. Filled circles correspond to ice-core records (red: Greenland, black: other) and filled diamonds to marine records. Error bars denote the $90 \%$ confidence interval of the estimated variance ratios. The data have a Spearman's rank correlation coefficient of $0.43(p \leq 0.03)$ when including, and of $0.35(p \leq 0.09)$ when exluding the Greenland ice cores. 


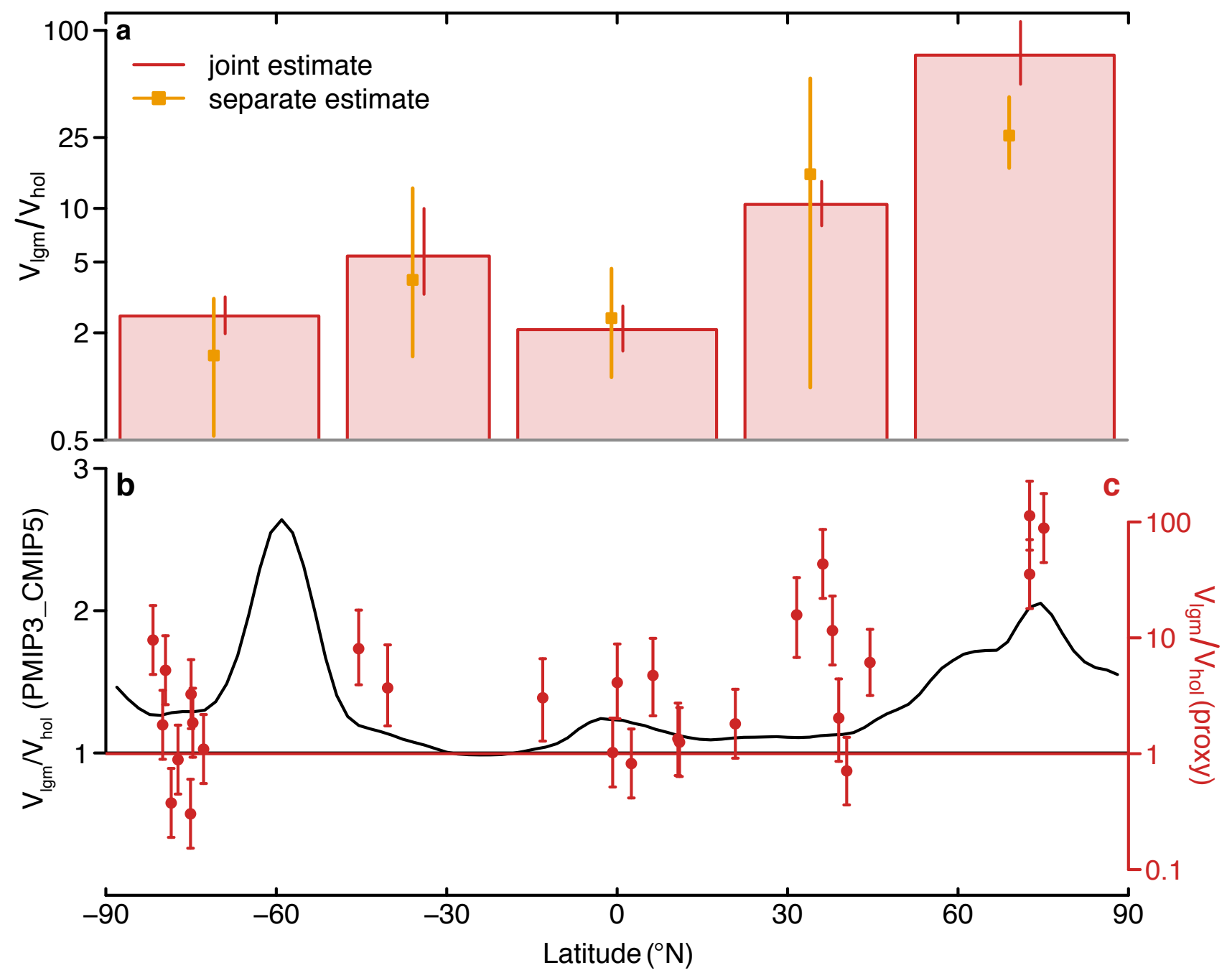

EDF 3: Proxy- versus model-based variability change. a, Zonal-mean LGM-to-Holocene variability change from the proxy compilations (red bars denote the joint estimate, orange points the separate estimate). b, Interannual to multidecadal zonal-mean variability change based on the PMIP3-CMIP5 simulations for the LGM and the pre-industrial period. c. Individual variability change at the proxy locations from the joint dataset. Error bars in a show the $90 \%$ confidence interval of the mean, error bars in c the $90 \%$ confidence interval of the individual variance ratios. 


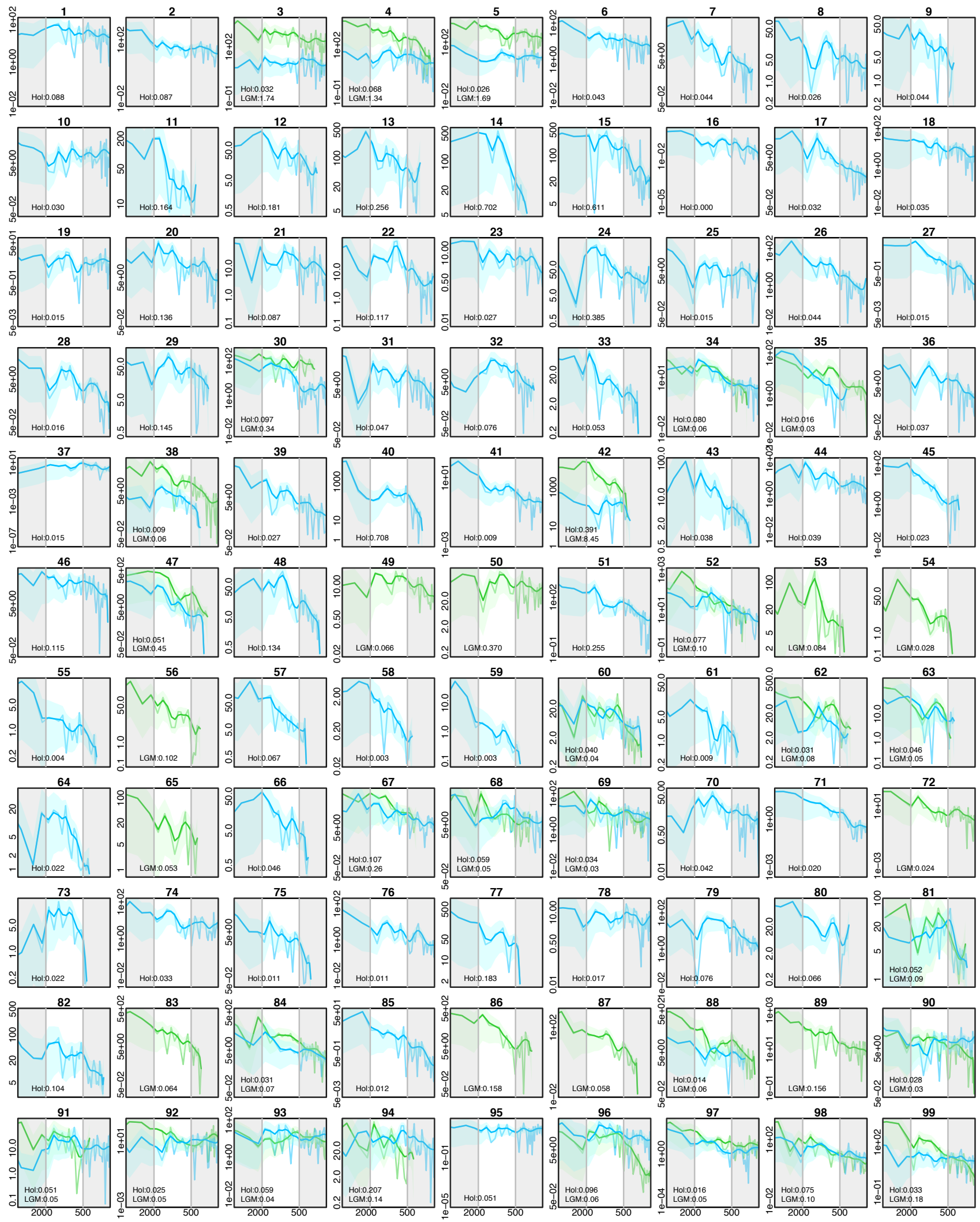

EDF 4: Raw periodograms of all records. Thin blue lines show the spectra of the Holocene time slice, thin green lines of the LGM time slice. Logarithmically smoothed spectra are given as thick lines with $90 \%$ confidence intervals as shading. Grey areas shade the frequency response outside the bandwidth used for the timescale-dependent variance ratio estimate. $x$-axis scaling is in periods in years, $y$-axis scaling denotes power spectral density. Text insets give the time-slice variances for the LGM and the Holocene ('Hol') in $\mathrm{K}^{2}$; variance ratios for the records from the joint dataset are listed in Extended Data Table 2. 
a

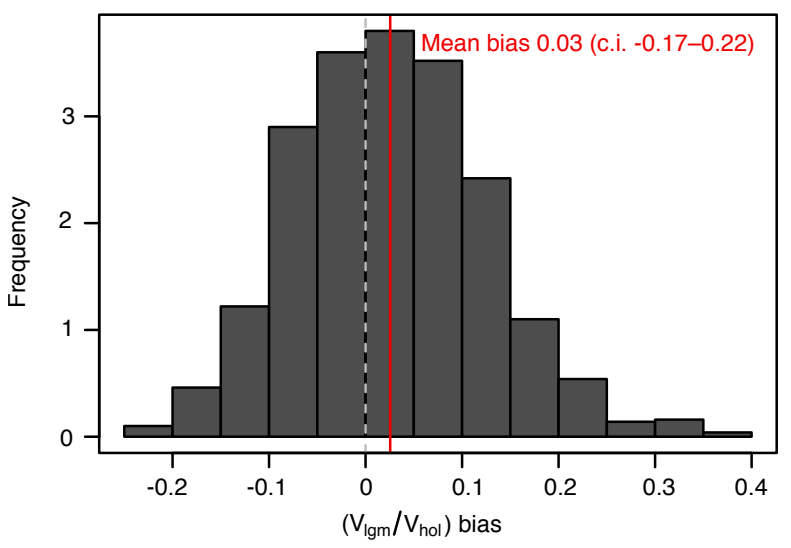

b

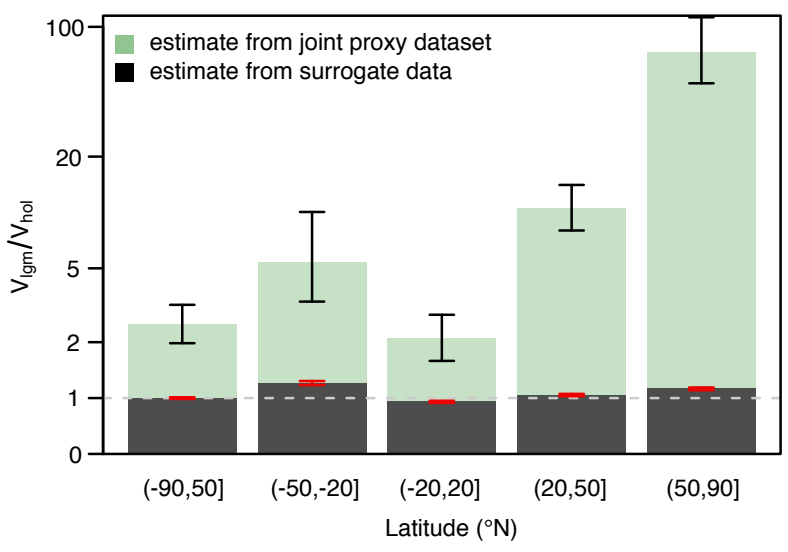

EDF 5: Surrogate tests for the magnitude of variance change. The magnitude of potential biases in the variance ratio estimates were derived using 1,000 realizations of power law noise (slope $\beta=1$ ) of constant variance on the original time axes of the records. Analyses for variability quantification were performed as for the primary analyses and described in the Methods. a, Histogram of the bias of the variance ratio estimated from the surrogate data. The mean of the distribution (red line) is not significantly different from zero (c.i., confidence interval). b, Estimated zonal-mean ratios from the surrogate data. The individual surrogate zonal-mean ratios (black bars) are all close to 1 and show no latitudinal pattern, in contrast to the zonal-mean ratios from the proxy data (joint dataset, green bars). Error bars show the $90 \%$ confidence interval for the proxy data and \pm 2 times the standard error of the zonal-mean for the surrogate data $(n=1,000)$. 


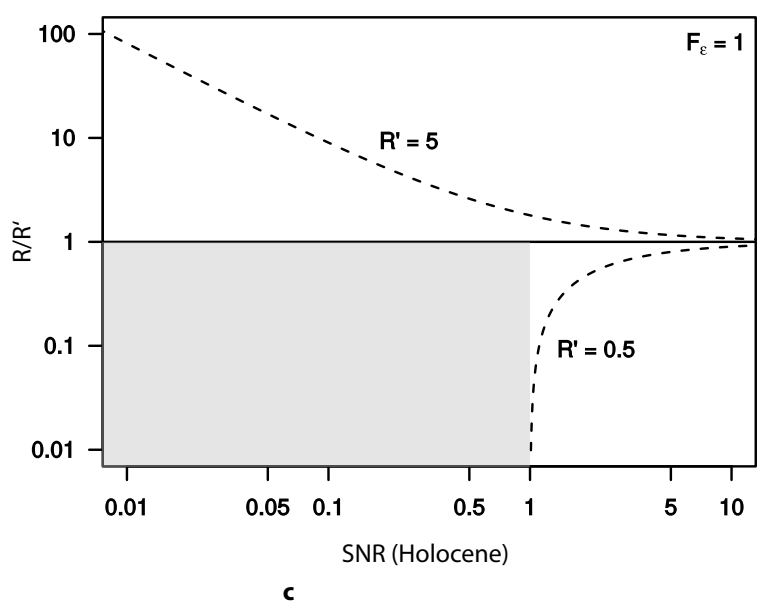

b

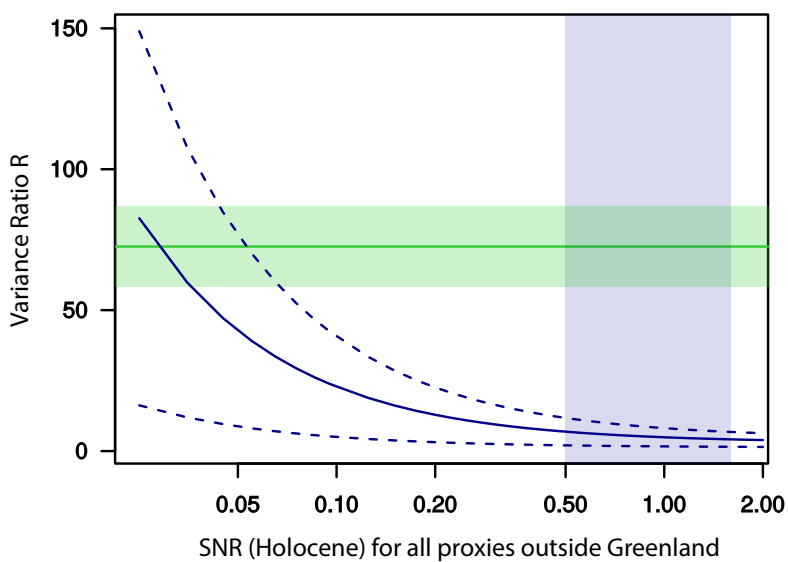

\begin{tabular}{lllll}
\hline Domain & Estimate $(\mathrm{Cl})$ & Method & Timescale & Ref. \\
\hline Central Greenland (Milcent \& Crete) & $1.25(0.6)$ & correlation & interannual & [50] \\
Central Greenland (NEEM) & 2.7 & correlation & interannual & {$[51]$} \\
Marine Mg/Ca (global) & 0.5 & forward model & centennial & {$[17]$} \\
Marine UK'37 (global) & 1.6 & forward model & centennial & [17] \\
East Antarctica (EDML) & $1.0(0.5)$ & correlation & seasonal & [52] \\
\hline
\end{tabular}

EDF 6: Impact of Holocene signal-to-noise ratio of proxy records on the noise correction of variance ratios estimated. a, Noise correction as a function of the Holocene signal-to-noise ratio (SNR). The ratio of the true variance ration to the estimated variance one, $R / R^{\prime}$, is displayed for $R^{\prime}=0.5$ and $R^{\prime}=5$ (dashed lines) for a noise variance ratio of $F_{\varepsilon}=1$. The shaded area denotes the region where for $R^{\prime}=0.5$, no $R / R^{\prime} \geq 0$ exists. $\mathbf{b}$, Test for the comparability of marine and Greenland ice core variance ratios as a function of the signal-to-noise ratio. The expected true variance ratio $R$ for the mean over all records of the joint dataset below $70^{\circ} \mathrm{N}$ is shown under the assumption of a wide range of signal-to-noise ratios (solid blue line) with uncertainty (dashed line) of \pm 2 times the s.e.m. $(n=25)$. Within the realistic range of Holocene signal-to-noise ratios (shaded blue area based on the published estimates listed in c), the noise-corrected global variance ratio (excluding Greenland) ranges from 1.7 to 11.4, which cannot be brought into agreement with the mean variance ratio of the Greenland ice cores (horizontal green line; shading denotes full uncertainty including the range of Greenland signal-to-noise ratios (c) used in the noise correction). c, Overview of published [50, 51, 17, 52] proxy signal-to-noise ratio estimates for the Holocene. Greenlandic and Antarctic estimates refer to $\delta^{18} \mathrm{O}$. CI, confidence interval. 


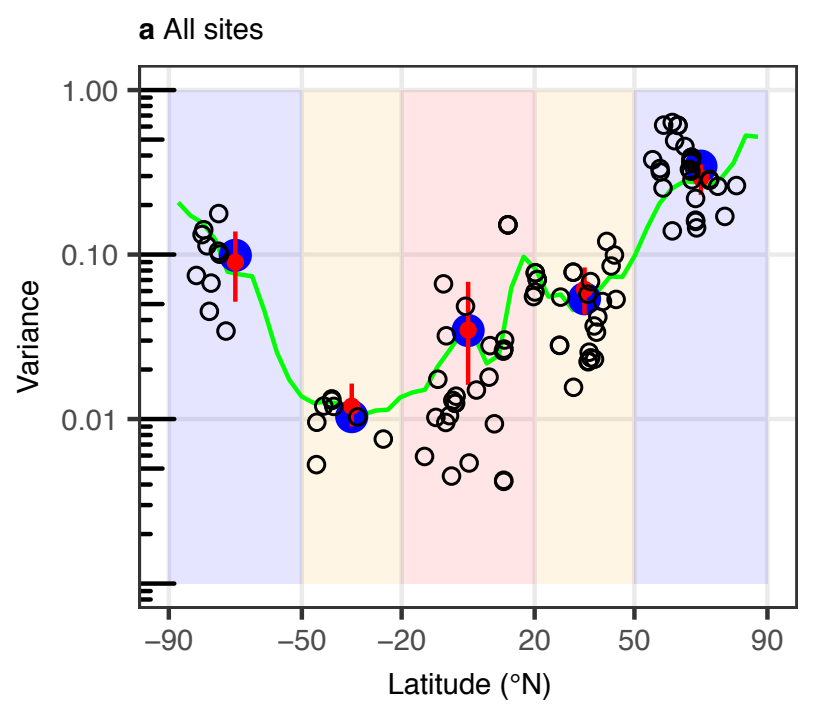

b Holocene \& LGM (joint dataset)

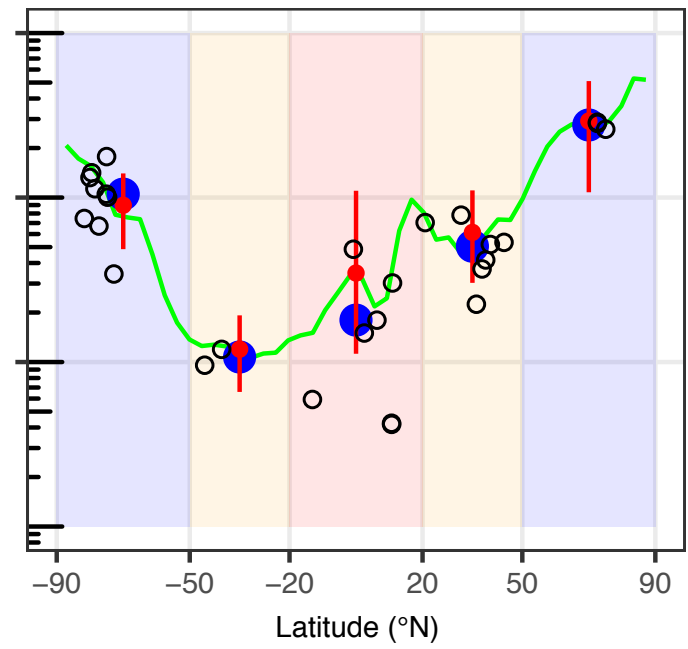

O Variability at proxy sites

Zonal box mean, all gridpoints

Zonal box mean, only proxy sites

_ Zonal mean, all gridpoints

EDF 7: Representativeness of the proxy data locations. The centennial temperature variability in the TraCE-21K simulation, sampled at the proxy locations (black circles), the zonal-mean variability (green line) and the mean of the variability in the zonal box, either formed only from the variance at the proxy sites (blue) or formed using all gridpoints (red), are shown. The red vertical lines show the $90 \%$ quantiles from the mean of $N$ random samples of the variance field, where $N$ is the number of proxy sites in the zonal box. a, Results when sampling from the proxy locations of the separate dataset. $\mathbf{b}$, Results when sampling from the joint dataset. In all cases the mean of the proxy sites is inside the distribution of random samples, which demonstrates that under the assumption of this variance field the proxy estimates are unbiased. 


\section{Extended Data tables (EDT)}

\begin{tabular}{lccccc}
\hline Site & Lat. $\left({ }^{\circ} \mathrm{N}\right)$ & Lon. $\left({ }^{\circ} \mathrm{E}\right)$ & Proxy & R $(90 \%$ c.i. $)$ & Ref. \\
\hline MSM5-5-712-2 & 78.9 & 6.8 & PBIP25 & $2.1(1.1-4.1)$ & {$[57]$} \\
MSM5-5-712-2 & 78.9 & 6.8 & IP25 & $11.2(5.6-22.1)$ & {$[57]$} \\
JM11-Fl-19PC & 62.8 & -3.9 & PBIP25 & $14.1(5.8-35.8)$ & {$[58]$} \\
\hline
\end{tabular}

EDT 1: North Atlantic sea-ice variability ratios. The variance ratios $R$ are listed, based on sea-ice reconstructions from three North Atlantic records[57, 58] (two sites, one based on two different sea ice proxies). 


\begin{tabular}{|c|c|c|c|c|c|c|c|}
\hline No. & Record & $\mathbf{R}_{\text {est }}$ & $\mathbf{R}_{\text {calib }}$ (lower) & $\mathbf{R}_{\text {calib }}$ (upper) & $\mathbf{R}_{\text {est }}$ (5\% quantile) & $\mathbf{R}_{\text {est }}$ (95\% quantile) & $\mathbf{R}_{\text {raw }}$ \\
\hline 3 & NGRIP & 88.6 & 28.8 & 103.8 & 44.7 & 175.8 & 53.6 \\
\hline 4 & GISP2 & 35.5 & 11.7 & 42 & 17.9 & 70.4 & 21.7 \\
\hline 5 & GRIP & 113.4 & 36.8 & 132.6 & 57.1 & 224.9 & 68.4 \\
\hline 30 & MD01-2412 & 6.1 & 3.2 & 4 & 3.2 & 11.8 & 3.6 \\
\hline 34 & PC-6 & 0.7 & 0.8 & 1 & 0.4 & 1.4 & 0.9 \\
\hline 35 & MD03-2699 & 2 & 1.3 & 1.7 & 0.9 & 4.4 & 1.5 \\
\hline 38 & MD01-2444 & 11.6 & 5.6 & 7.1 & 5.8 & 22.9 & 6.3 \\
\hline 42 & ODP976-4 & 43.5 & & & 21.9 & 86.2 & 22.2 \\
\hline 47 & MD98-2195 & 15.8 & 7.4 & 9.5 & 6.8 & 33.1 & 8.4 \\
\hline 52 & ODP658C-Zhao & 1.8 & 1.2 & 1.6 & 0.9 & 3.6 & 1.4 \\
\hline 60 & SK237-GC04 & 1.3 & 1 & 1.3 & 0.6 & 2.5 & 1.1 \\
\hline 62 & ODP1240 & 4.1 & & & 2 & 8.8 & 2.6 \\
\hline 63 & PL07-39PC & 1.3 & 1 & 1.3 & 0.6 & 2.7 & 1.2 \\
\hline 67 & MD98-2181 & 4.7 & 2.5 & 3.3 & 2.1 & 9.9 & 2.9 \\
\hline 68 & MD03-2707 & 0.8 & 0.8 & 1 & 0.4 & 1.6 & 0.9 \\
\hline 69 & SO189-39KL & 1 & 0.9 & 1.2 & 0.5 & 2 & 1 \\
\hline 81 & MD01-2378 & 3 & 1.8 & 2.3 & 1.3 & 6.6 & 2 \\
\hline 84 & MD97-2121 & 3.7 & 2.1 & 2.7 & 1.7 & 8.7 & 2.4 \\
\hline 88 & MD97-2120 & 8.1 & 4 & 5.1 & 3.9 & 17.4 & 4.5 \\
\hline 90 & Talos Dome & 1.1 & 0.5 & 2.4 & 0.6 & 2.2 & 1 \\
\hline 91 & Dome C & 1.9 & 0.6 & 3.2 & 0.9 & 3.7 & 1.4 \\
\hline 92 & EPICA DML & 3.3 & 0.9 & 4.8 & 1.6 & 6.5 & 2.1 \\
\hline 93 & EPICA Dome C & 0.3 & 0.3 & 1.5 & 0.2 & 0.6 & 0.7 \\
\hline 94 & Dome F & 0.9 & 0.4 & 2.1 & 0.4 & 1.8 & 0.9 \\
\hline 96 & Vostok & 0.4 & 0.3 & 1.5 & 0.2 & 0.7 & 0.7 \\
\hline 97 & WAIS Divide & 5.3 & 1.4 & 7 & 2.7 & 10.4 & 3.1 \\
\hline 98 & Byrd & 1.8 & 0.6 & 3.1 & 0.9 & 3.5 & 1.4 \\
\hline 99 & Siple Dome & 9.6 & 2.4 & 11.9 & 4.8 & 19 & 5.3 \\
\hline
\end{tabular}

EDT 2: Individual variability ratio estimates for all records from the joint dataset. The estimate used throughout the paper is the noise-corrected variance ratio $R_{\text {est }}$ (first data column). $R_{\text {calib }}$ (lower/upper) denotes the results for the variance ratios when using the calibration parameters with the lower/upper limits of the calibration uncertainty for the LGM and the upper/lower calibration uncertainty limits for the Holocene. Data columns four and five give the $5 \%$ and $95 \%$ quantiles of the used estimate $\left(\mathrm{R}_{\text {est }}\right)$. Data column six gives the raw uncorrected ratio $\left(\mathrm{R}_{\text {raw }}\right)$. Numbers refer to the list of records given in the Supplementary Information. For ODP976-4 and ODP1240, no calibration uncertainty estimate is available. 